\title{
Strategic Developments Linking to the Cost of Managment of Childhood Pneumonia from 1968 to 2018:A Bibliometric Analysis
}

\author{
Dongmei Pei ${ }^{1}$, Xinyue Fan ${ }^{1}$, Chengpu Zhang ${ }^{1}$, TengFei Yang ${ }^{1}$, and Chong Zhang ${ }^{1}$ \\ ${ }^{1}$ Shengjing Hospital of China Medical University
}

June 1, 2020

\begin{abstract}
Abstract Background Childhood pneumonia, the most common disease of young, not only presents diverse challenges to healthcare providers and parents, but also carries the vast financial burden to medical care system. Using bibliometric analysis, we probed the pivotal strategic developments associated with costs of management of this disorder affecting millions of children worldwide and identified the research hotspots and trends over the time span of 50 years. Methods We retrieved relevant data from the Pubmed database in a range of 50 years from 1968 to 2018 using select medical subject headings. In addition, the research hotspots concerning the cost of childhood pneumonia using co-word clustering analysis and strategic diagrams were identified. Results A total of 1728 articles were retrieved for the specified time period and number of relevant publications trended to gradually increase. The authors from the USA contributed to the greatest number of articles. The Journal of Vaccine apparently published the most relevant articles. Madhi SA is the most prolific author from National Health Laboratory Service of University of the Witwatersrand in Johannesburg, South Africa, with a total of 8 papers. The keyword with the highest frequency was "pneumonia/epidemiology", followed by "hospitalization/statistics \&numerical data" and "pneumococcal vaccines/economics, respectively. Conclusion Research on the expenditure of childhood pneumonia covered a wide range of key subjects along with multiple hot topics. Among them, the epidemiology and hospitalization were prioritized in the studies conducted by various authors.
\end{abstract}

\section{Hosted file}

2020Pei-et_al-Manuscript.doc available at https://authorea.com/users/328615/articles/455799strategic-developments-linking-to-the-cost-of-managment-of-childhood-pneumonia-from1968-to-2018-a-bibliometric-analysis 

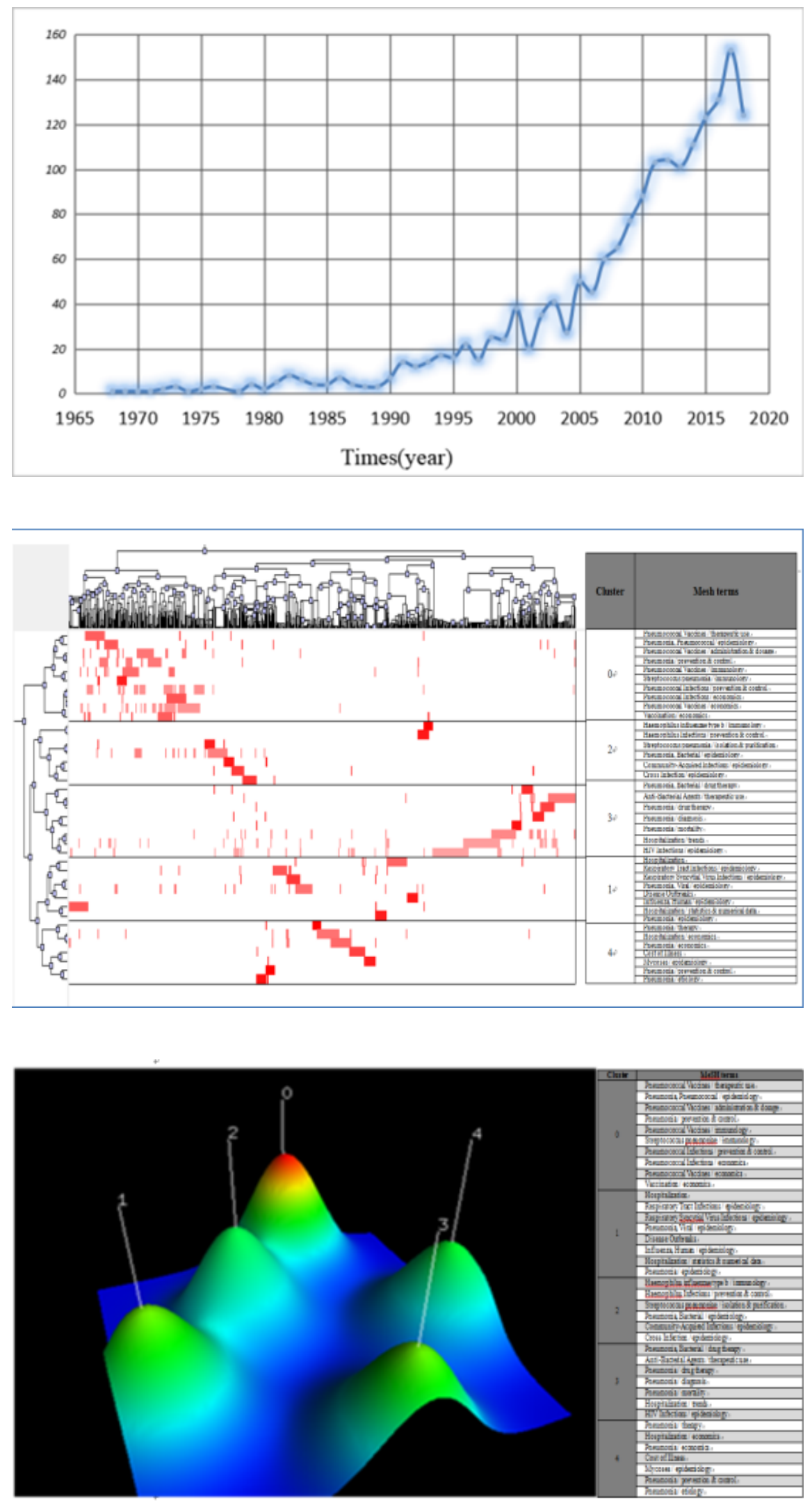

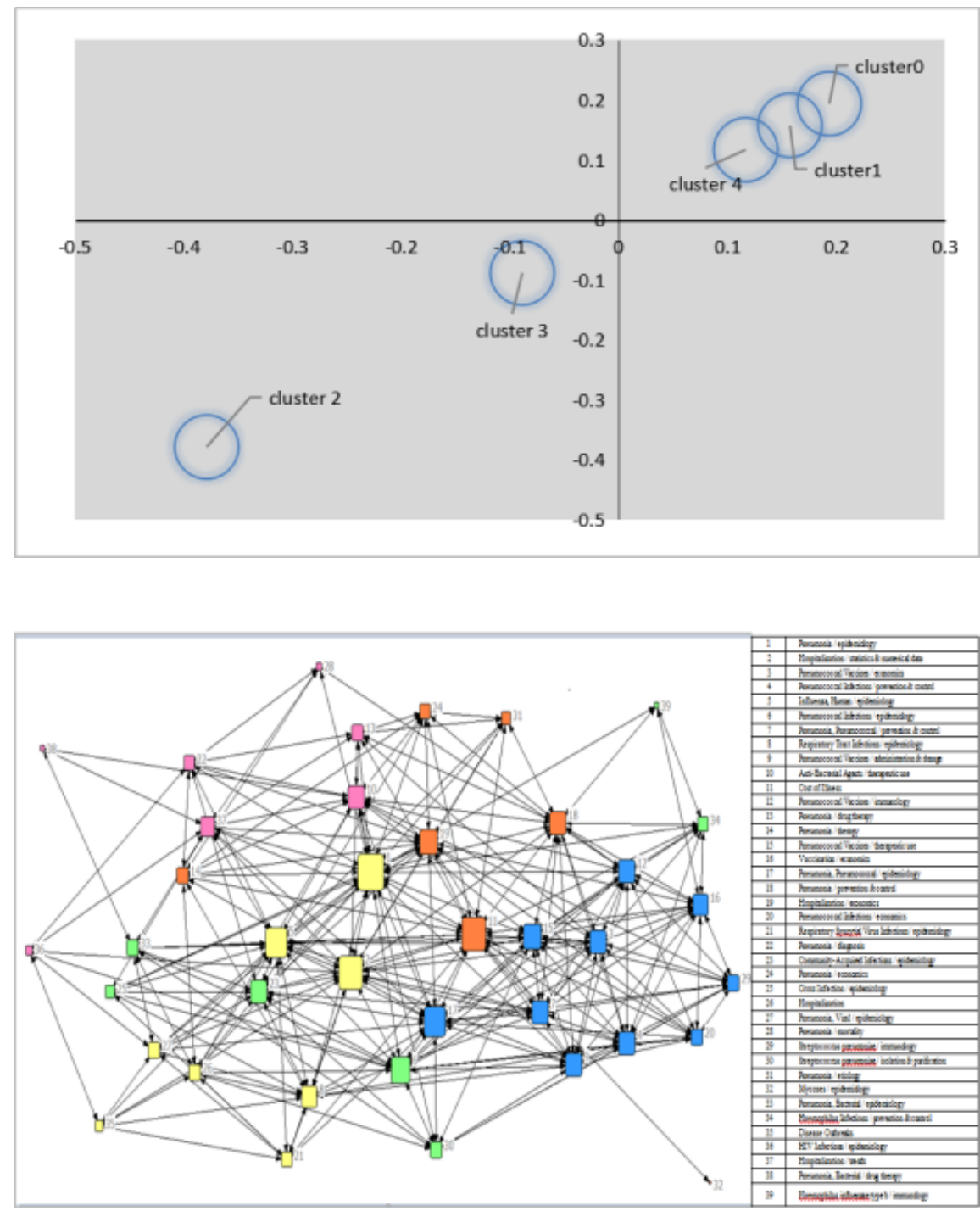

\section{Hosted file}

Table 1 cost of management of pneumonia.doc available at https://authorea.com/users/328615/ articles/455799-strategic-developments-linking-to-the-cost-of-managment-of-childhoodpneumonia-from-1968-to-2018-a-bibliometric-analysis

\section{Hosted file}

Table 2 The total number of publications.doc available at https://authorea.com/users/328615/ articles/455799-strategic-developments-linking-to-the-cost-of-managment-of-childhoodpneumonia-from-1968-to-2018-a-bibliometric-analysis

\section{Hosted file}

Table 3.doc available at https://authorea.com/users/328615/articles/455799-strategicdevelopments-linking-to-the-cost-of-managment-of-childhood-pneumonia-from-1968-to-2018a-bibliometric-analysis

\section{Hosted file}


Table 4.doc available at https://authorea.com/users/328615/articles/455799-strategicdevelopments-linking-to-the-cost-of-managment-of-childhood-pneumonia-from-1968-to-2018a-bibliometric-analysis

\section{Hosted file}

Table 5.doc available at https://authorea.com/users/328615/articles/455799-strategicdevelopments-linking-to-the-cost-of-managment-of-childhood-pneumonia-from-1968-to-2018a-bibliometric-analysis 